\title{
Evaluation of the predictive value of Her-2/neu gene expression on osteosarcoma therapy in laser-microdissected paraffin-embedded
} tissue

\author{
Joerg Fellenberg ${ }^{1}$, Alexandra Krauthoff ${ }^{1}$, Konstantin Pollandt ${ }^{2}$, Guenter Delling ${ }^{2}$ and \\ Dominik Parsch ${ }^{1}$ \\ ${ }^{1}$ University Hospital for Orthopaedic Surgery Heidelberg, Heidelberg, Germany and ${ }^{2}$ Institute of \\ Osteopathology, University Hospital Hamburg-Eppendorf, Germany
}

\begin{abstract}
Histologic response to chemotherapy is currently the strongest prognostic factor in high-grade osteosarcoma, but it can only be assessed after several weeks of therapy. Thus, detection of chemosensitivity at the time of diagnosis would be of great clinical importance. The expression of the proto-oncogene Her-2/neu has been shown to be of predictive value in breast cancer and has also been considered as prognostic marker for osteosarcomas, but reports of mainly immunohistochemical studies are controversial. Therefore, the aim of this study was to investigate Her-2/neu gene expression in laser-microdissected osteosarcoma cells. Laser microdissection enables the precise isolation of morphological defined cells from archival tissue specimens and is in combination with the highly sensitive real-time RT-PCR technique a valuable tool for cell-specific analysis of gene expression. Through optimization of current protocols, we could show that this technique can be successfully applied on formalin-fixed, paraffin-embedded and decalcified osteosarcoma tissue with high sensitivity and reproducibility. In all 17 osteosarcoma biopsies analyzed, we could detect Her-2/neu gene expression. Expression correlated significantly with the response to preoperative chemotherapy, which was assessed histologically according to the six-grade scale of Salzer-Kuntschik. Risk assessment on the basis of increased Her-2/neu gene expression matched the histologic findings in 16 out of 17 cases $(94 \%)$. These data demonstrate the reliability of laser microdissection in the analysis of gene expression and suggest a possible role of Her-2/neu as prognostic marker for therapy outcome in osteosarcomas.
\end{abstract}

Laboratory Investigation (2004) 84, 113-121, advance online publication, 20 November 2003; doi:10.1038/labinvest.3700006

Keywords: osteosarcoma; cancer; laser microdissection; gene expression; chemotherapy

Osteogenic sarcoma is the most common primary tumor of the bone, typically affecting the long tubular bones of children and adolescents. The identification of effective chemotherapy significantly improved the outcome with long-term relapse free survival rates ranging from 55 to $75 \%$ over the last several decades. ${ }^{1,2}$ On the other hand, the remainder of patients will relapse most often with pulmonary metastases. These patients poorly respond to chemotherapy. ${ }^{3}$ Therefore, a need exists to stratify patients at diagnosis into low-and high-risk groups improving the outcome of high-risk patients

Correspondence: Dr J Fellenberg, Stiftung Orthopädische Universitätsklinik Heidelberg, Schlierbacher Landstr. 200a, 69118 Heidelberg, Germany.

E-mail: joerg.fellenberg@ok.uni-heidelberg.de

Received 12 July 2003; revised 22 September 2003; accepted 02 October 2003; published online 20 November 2003 and minimizing the toxicity of therapy for low-risk patients by means of a risk-adapted therapy. Histologic response of the tumor to chemotherapy is currently the strongest predictive factor of outcome but can only be assessed after several weeks of therapy. ${ }^{1,4}$ Yet, beside clinical stage, there are no prognostic indicators with sufficient predictive value at the time of diagnosis. Several parameters have been investigated for their relation to outcome, including tumor size and localization, serum levels of lactate dehydrogenase and alkaline phosphatase and expression of P-glycoprotein, but have not been shown to be consistently predictive. ${ }^{5-8}$

The Her-2/neu proto-oncogene (also called erbB2) located on human chromosome 17 encodes a $185 \mathrm{kDa}$ transmembrane glycoprotein with tyrosine kinase activity that shares extensive sequence homology with the epidermal growth factor receptor gene. ${ }^{9}$ Overexpression of Her-2/neu has been shown 
in a variety of human tumors including breast, ${ }^{10}$ lung ${ }^{11}$ and ovarian carcinomas. ${ }^{12}$ In addition, Her-2/ neu overexpression could be correlated with poor prognosis in patients with breast cancer ${ }^{13}$ and has been proposed as possible target for tumor therapy. ${ }^{14-16}$

Several reports have suggested that Her-2/neu overexpression may also be of predictive value for osteosarcoma therapy but the results are controversial. Using immunohistochemical assays, some studies demonstrated Her-2/neu overexpression in osteosarcoma tissues, which strongly correlated with early pulmonary metastases, less tumor necrosis after preoperative chemotherapy and a significantly decreased event-free survival rate. ${ }^{17-19}$ Other studies did not observe any Her-2/neu expression or only cytoplasmic expression ${ }^{20}$ which is in contrast to membranous positivity considered as non-specific. In these studies, observation of cytoplasmic positivity was independent of histologic subtype and grade and not associated with response to preoperative chemotherapy or disease progression. $^{21,22}$ On the other hand, a correlation of cytoplasmic Her-2/neu positivity with a shorter overall metastasis-free survival has recently been reported. ${ }^{23}$ These discrepancies have extensively been discussed in the literature and attributed mainly to technical issues including the type of tissue, fixation method, storage conditions, sensitivity and reliability of the antibodies used, the scoring system and the interpretation of the results. ${ }^{24,22}$

Owing to the methodical problems concerning immunohistochemical analysis of Her-2/neu, we focused on the evaluation of the prognostic significance of Her-2/neu gene expression on the outcome of osteosarcoma therapy. However, a major disadvantage in the analysis of normal or neoplastic tissues using conventional techniques is the cellular heterogeneity of most tissue samples. The results of such studies crucially depend on the abundance of the cells of interest and are highly influenced by contaminating bystander cells. The recently developed laser microdissection overcomes this obstacle and allows the analysis of a well defined cell population. ${ }^{25-27}$ In combination with real-time quantitative reverse transcription-polymerase chain reaction (RT-PCR), minute amounts of RNA can be quantified even in archival material. However, the majority of archival material available for molecular analysis is represented by formalin-fixed paraffinembedded tissues. In consequence of extensive crosslinking and chemical modification of the nucleic acids caused by formalin fixation and decalcification, only small amounts of highly fragmented RNA can be isolated from these samples. ${ }^{28-32}$

Therefore, the aim of this study was to establish and optimize the procedure of quantitative gene expression analysis in laser-microdissected, paraffin-embedded osteosarcoma tissues and to apply this technique on the evaluation of the prognostic value of Her-2/neu expression on therapy outcome.

\section{Materials and methods}

\section{Patients}

Formalin-fixed paraffin-embedded specimens from 17 osteosarcoma biopsies were retrieved from the archive of the Institute of Osteopathology of the University Hospital Hamburg-Eppendorf.

Response to preoperative chemotherapy was assessed histologically according to the six-grade scale of Salzer-Kuntschik et $a l^{33}$ where grade 1 denotes no viable tumor cells; grade 2, solitary viable cells or one islet of less than $0.5 \mathrm{~cm}$; grade 3 , less than $10 \%$; grade $4,10-50 \%$; grade 5 , more than $50 \%$ and grade 6 , no effect of chemotherapy. A good response was defined as less than $10 \%$ viable tumor cells corresponding to response grades $1-3$.

\section{Preparation of Samples}

For microdissection the paraffin-embedded osteosarcoma tissues were cut in $10 \mu \mathrm{m}$ sections and mounted on $0.17 \mathrm{~mm}$ glass slides (PALM Microlaser Technologies AG, Bernried, Germany) covered with a $1.35 \mu \mathrm{m}$ thin polyethylene-naphthalene membrane (PALM). Prior to tissue mounting, the membrane was UV-irradiated to overcome the hydrophobic nature of the membrane. Sections were deparaffinized in two changes of XEM-200 (Vogel GmbH, Giessen, Germany) for $2 \mathrm{~min}$, rehydrated in $100 \%$ ethanol, $96 \%$ ethanol and $70 \%$ ethanol, for $1 \mathrm{~min}$ each and briefly washed in distilled water (Invitrogen, Karlsruhe, Germany). Sections were stained for $1 \mathrm{~min}$ in Mayer's hematoxylin solution (Sigma, Deisenhofen, Germany), blued in $0.025 \%$ sodium bicarbonate (Sigma) for $2 \mathrm{~min}$, washed in distilled water (Invitrogen), counterstained for 2 min in eosin Y solution (Sigma), washed again in distilled water and air dried for $30 \mathrm{~min}$.

\section{Microdissection}

Microdissection was carried out using the MicroBeam system from PALM Microlaser Technologies, which consists of a pulsed, low-energy $337 \mathrm{~nm}$ nitrogen laser coupled into an inverted microscope (Axiovert 200, Carl Zeiss, Göttingen, Germany). The tumor cells were localized and marked under the microscope and catapulted into the cap of $0.5 \mathrm{ml}$ PCR reaction tubes (PALM) that have been DEPC-treated and autoclaved before use. Immediately before catapulting, the caps were coated with $1 \mu \mathrm{l}$ mineral oil (Sigma) to enhance the adherence of the specimen. Prior to the laser-mediated transfer, the specimen was isolated by laser microbeam microdissection, forming a clear-cut gap around the selected area. 
After catapulting the cells of interest, the caps were put on the corresponding tubes containing $1 \mu \mathrm{l}$ PCR-grade proteinase K (14-22 mg/ml, Roche, Mannheim, Germany) and $40 \mu \mathrm{l}$ proteinase $\mathrm{K}$ digestion buffer (10 mM Tris-HCl pH 8.0, 0.1 mM EDTA pH 8.0, $2 \%$ SDS) and centrifuged at $14000 \mathrm{rpm}$ for $2 \mathrm{~min}$. Digestion was carried out at $56^{\circ} \mathrm{C}$ for $16 \mathrm{~h}$.

\section{RNA Extraction and Reverse Transcription}

Total RNA was extracted using the Absolutely RNA ${ }^{\mathrm{TM}}$ Nanoprep kit (Stratagene, Amsterdam, Netherlands). This kit allows rapid purification of high-quality RNA from extremely small samples like cells harvested by laser microdissection. The included DNase digestion removes contaminating genomic DNA, which would disturb downstream quantification analysis. Lysis buffer $(100 \mu \mathrm{l})$ was added to the proteinase $\mathrm{K}$ digestion mixture and extraction of RNA was carried out according to the manufacturer's protocol. Finally, RNA was eluted in $15 \mu$ l elution buffer.

Reverse transcription was performed using $1 \mu \mathrm{l}$ Sensiscript $^{\mathrm{TM}}$ reverse transcriptase (Qiagen, Hilden, Germany), $0.5 \mathrm{mM}$ dNTPs, $250 \mathrm{ng}$ random primer (Invitrogen), $10 \mathrm{U}$ RNase inhibitor (Invitrogen) and $13.5 \mu \mathrm{l}$ RNA in a total volume of $20 \mu \mathrm{l}$. The reaction was carried out at $37^{\circ} \mathrm{C}$ for $2 \mathrm{~h}$.

\section{Preamplification and Real-time Quantitative PCR}

A standard PCR was used for preamplification of the target sequences. To minimize DNA cross-contamination and contamination of samples by PCR product carry-over, an additional DNase digestion step was performed. The PCR mix containing $0.2 \mathrm{mM}$ dNTPs, $1.5 \mathrm{mM} \mathrm{MgCl}_{2}, 2 \mu \mathrm{l} 10 \times$ PCR buffer and $0.5 \mu \mathrm{l}$ DNaseI (Stratagene) in a total volume of $18.25 \mu \mathrm{l}$ was incubated for $20 \mathrm{~min}$ at $37^{\circ} \mathrm{C}$ in a thermal cycler. DNAse was inactivated by heating to $94^{\circ} \mathrm{C}$ for $10 \mathrm{~min}$ before $1 \mu \mathrm{l} \mathrm{cDNA}, 0.25 \mu \mathrm{l}$ of each primer and $0.25 \mu \mathrm{l}$ Platinum Taq polymerase (Invitrogen) were added. Samples were heated to $94^{\circ} \mathrm{C}$ for 3 min followed by 15 cycles of denaturation at $94^{\circ} \mathrm{C}$ for $20 \mathrm{~s}$, annealing at $58^{\circ} \mathrm{C}$ for $30 \mathrm{~s}$ and extension at $72^{\circ} \mathrm{C}$ for $45 \mathrm{~s}$ and a final extension step at $72^{\circ} \mathrm{C}$ for $7 \mathrm{~min}$. To avoid false-positive amplification of genomic DNA, primers were designed to span 2 exons. The following primers were used:

\section{PBGD-F: 5'-GACCTGGTTGTTCACTCCTT-3' PBGD-R: 5'-GGTGAAAGACAACAGCATC- ${ }^{\prime}$ Her-2-F: 5'-GGGAAACCTGGAACTCACCT-3' Her-2-R: 5'-TGTGAGCGATGAGCACGTA-3'}

Quantitative real-time PCR was performed in a LightCycler instrument (Roche Diagnostics) in a total volume of $20 \mu \mathrm{l}$ using the LightCycler FastStart DNA Master SYBR Green I kit (Roche Diagnostics) and $2 \mu \mathrm{l}$ of the PCR product as template. Samples were heated to $95^{\circ} \mathrm{C}$ for $10 \mathrm{~min}$ followed by 40 cycles of denaturation at $95^{\circ} \mathrm{C}$ for $0 \mathrm{~s}$, annealing at $58^{\circ} \mathrm{C}$ for
$7 \mathrm{~s}$ and extension at $72^{\circ} \mathrm{C}$ for $14 \mathrm{~s}$. After the last cycle, a melting curve analysis was performed to verify the specificity of the amplified PCR products. The following nested primers were used:

\section{PBGD-NF: 5'-GACCTGGTTGTTCACTCCTT-3' \\ PBGD-NR: $5^{\prime}$-GGCTCCGATGGTGAAGCC-3' \\ Her-2-NF: 5'-CACCTACCTGCCCACCAAT- ${ }^{\prime}$ \\ Her-2-NR: 5'-CACGTAGCCCTGCACCTC-3'}

The amount of PCR product was calculated using an external standard curve and LightCycler software. Calculated Her-2/neu expression was normalized on the basis of the porphobilinogen deaminase (PBGD) expression in the corresponding samples.

\section{Immunohistochemistry}

Immunohistochemical detection of Her-2/neu was carried out using a monoclonal anti-human c-ErbB2 antibody (BD Transduction Laboratories, Heidelberg, Germany) at a concentration of $0.2 \mu \mathrm{g} / \mathrm{ml}$. Paraffin sections were deparaffinized in XEM-200 (Vogel GmbH, Giessen, Germany) and rehydrated in alcohol. For detection the ImmunoCruz ${ }^{\mathrm{TM}}$ Staining System for use with mouse primary antibodies (Santa Cruz, Heidelberg, Germany) and 3,3'-diaminobenzidine (DAB) as substrate (Vector Laboratories, Burlingame, CA, USA) were used according to the manufacturers instructions.

All slides were counterstained with hematoxylin (Sigma, Taufkirchen, Germany) and mounted under glass coverslips using Aquatex (VWR International, Darmstadt, Germany).

\section{Results}

Effect of Amplicon Size on Gene Expression Analysis

To determine the optimal amplicon size for gene expression analysis in formalin-fixed paraffin-embedded osteosarcoma tissue, we designed a set of primers spanning 66-574bp of the housekeeping gene PBGD. PCR products were analyzed on ethidium-bromide stained gels and compared to the amplification products derived from cDNA obtained from the osteosarcoma cell line Saos-2. Figure 1 indicates a reduced amplification in the formalinfixed samples at $252 \mathrm{bp}$ and even no amplification at larger amplicon sizes. These data demonstrate the fragmentation of RNA in the formalin-fixed samples that requires amplicon sizes below $150 \mathrm{bp}$ for quantitative analysis.

\section{Prevention of False-Positive Amplification Products by DNase Treatment}

Owing to the very high sensitivity of this method, DNA-contaminations in the solutions and tubes used for PCR and PCR-template carry-over may lead to false-positive results that have to be excluded. We decided to implement a DNase digestion step before 


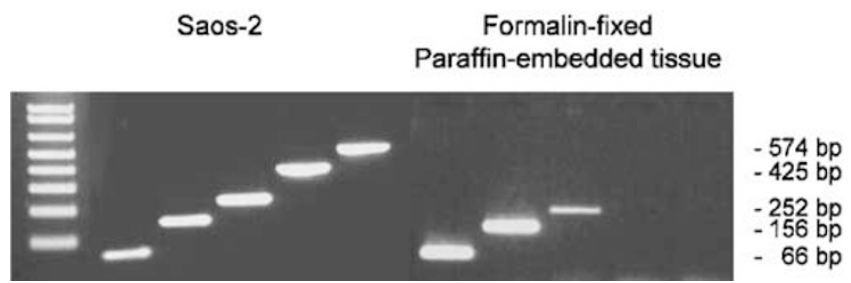

Figure 1 Amplification of different sized fragments of PBGD cDNA derived from laser-microdissected formalin-fixed and paraffinembedded tissue. Six primer pairs that amplify fragments ranging from 66 to $574 \mathrm{bp}$ were tested. RNA isolated from the cell line Saos-2 served as control. PCR products were separated on a $2 \%$ agarose gel and stained with ethidium bromide.
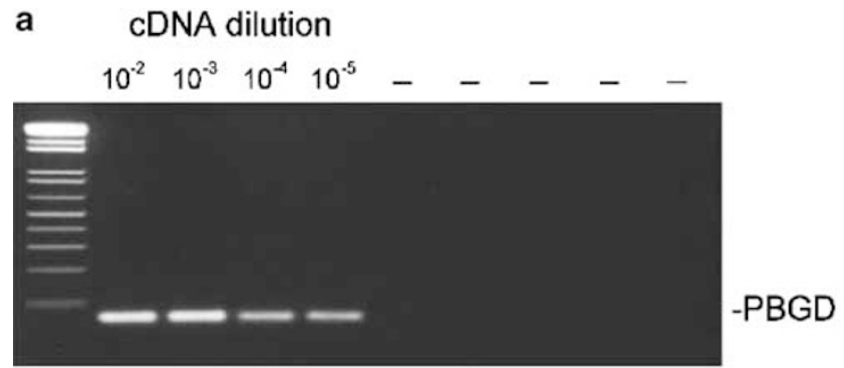

b

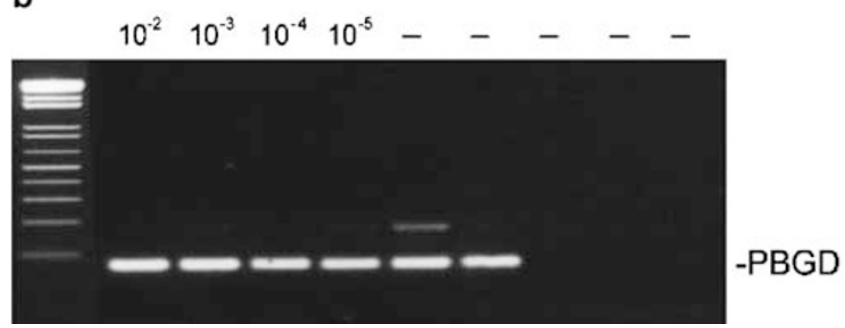

Figure 2 Porphobilinogen cDNA derived from Saos-2 cells was diluted as indicated and preamplified with (a) or without (b) DNase digestion. As negative control, five reactions were carried out without the addition of template $(-)$. A measure of $1 \mu$ l of the preamplification reaction mixture was subjected to a nested PCR consisting of 32 cycles. PCR products were separated on a $2 \%$ agarose gel and stained with ethidium bromide. A representative experiment is shown.

amplification of target sequences directly in the PCR reaction buffer. The effectiveness of this DNase preincubation on the prevention of false-positive amplification was tested using several dilutions of Saos-2 cDNA $\left(10^{-2}-10^{-5}\right)$ and control reactions without template. PBGD cDNA was amplified as described in Materials and methods with and without DNase digestion. Without DNase treatment, false-positive results were occasionally observed in the negative control reactions without template which could be completely abolished by DNase preincubation of the samples (Figure 2).

\section{Effect of Proteinase K Digestion on RNA Recovery}

The influence of proteinase $\mathrm{K}$ digestion on RNA extraction and the quantification of Her-2/neu mRNA was investigated using laser-microdissected osteosarcoma cells. Equal amouts of osteosarcoma cells were excised from paraffin-embedded samples and incubated for 2 or $16 \mathrm{~h}$ with proteinase $\mathrm{K}$ to digest the tissue. The amount of Her-2/neu ampli- fication product was semiquantitatively analyzed by PCR amplification, nested-PCR and gel electrophoresis. In contrast to only faint bands that could be detected in the absence of proteinase $\mathrm{K}$, a timedependent increase of signal intensity was observed in the proteinase K- treated samples (Figure 3).

\section{Effect of Target Amplification on Quantification Results}

The efficiency of target amplification by PCR is influenced by many factors like primer sequence, cDNA quality and template concentration. If, as in our study, it is necessary to amplify the target sequences, differences in PCR efficiency would lead to incorrect quantification results since the ratio between the gene of interest and the housekeeping gene that is used for normalization would not be constant. To exclude possible quantification errors due to target amplification Saos-2 cDNA was diluted 1:5000 and reamplified by PCR. The abundance of Her-2/neu and porphobilinogen cDNA was 


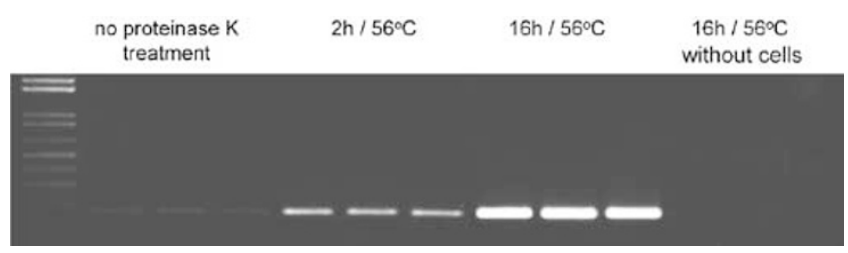

Figure 3 RNA was extracted from 200 laser-microdissected osteosarcoma cells in the absence of proteinase K or after incubation with proteinase $\mathrm{K}$ at $56^{\circ} \mathrm{C}$ for 2 and $16 \mathrm{~h}$, respectively. RNA was reverse transcribed, and porphobilinogen cDNA was amplified by nested PCR as described in Materials and methods. PCR products were separated on a $2 \%$ agarose gel and stained with ethidium bromide. As negative control, three reactions were carried out in the presence of proteinase K but without the addition of cells.

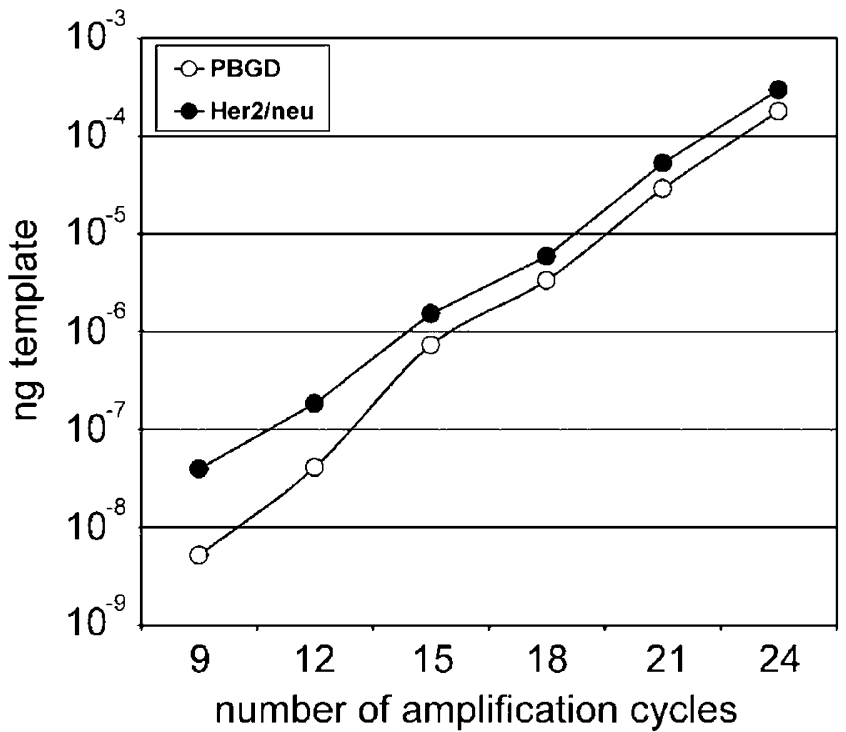

Figure $4 \mathrm{Her}-2 / \mathrm{neu}$ and PBGD cDNA was amplified by PCR using a 1:5000 dilution of Saos-2 cDNA as template. PCR products were quantified by a nested real-time quantitative PCR after the indicated number of cycles. Template concentrations were calculated by an internal standard curve and LightCycler software.

quantified by LightCycler after 9, 12, 15, 18, 21 and 24 cycles of amplification. The efficiencies of Her-2/ neu and PBGD amplification were comparable over a wide range of cycles. The detection limit was reached after six cycles of preamplification. Best quantification results were obtained when amplification was carried out 6-9 cycles over the detection limit. Thus, for further experiments, 15 cycles of preamplification were carried out before quantification (Figure 4).

\section{Sensitivity of Quantitative PCR Analysis of Laser- microdissected Paraffin-embedded Osteosarcoma Cells}

The combination of proteinase $\mathrm{K}$ digestion, DNase treatment of the RNA and the PCR reactions and amplification of the target sequences led to a highly reproducible and sensitive method to quantify mRNA expression even in decalcified and formalin-fixed specimen. Approximately 100 cells were sufficient to obtain enough cDNA for the analysis of 20 different genes (Figure 5).

\section{Quantification of Her-2/neu Expression in Laser microdissected Osteosarcoma Tissue}

To investigate the relationship between Her-2/neu gene expression and the response to preoperative chemotherapy, we analyzed Her-2/neu expression in 17 laser-microdissected osteosarcoma biopsies. Total RNA was extracted from approximately 200 cells isolated in duplicates from two different areas of the formalin-fixed samples and converted to cDNA. Her-2/neu and PBGD cDNA were amplified by PCR and quantified by a nested real-time quantitative PCR. Her-2/neu expression was normalized to the expression of the housekeeping gene PBGD and correlated to the histologically determined response to preoperative chemotherapy. In all samples analyzed, Her-2/neu expression could be detected. Expression was significantly elevated in patients with poor response as defined by more than $10 \%$ viable tumor cells after chemotherapy. Her-2/neu expression correlated significantly with response to chemotherapy as determined by MannWhitney $U$-test $(P=0.005)$. Defining a 1.3 -fold Her-2/neu expression as threshold for overexpression therapy outcome would have been predicted 


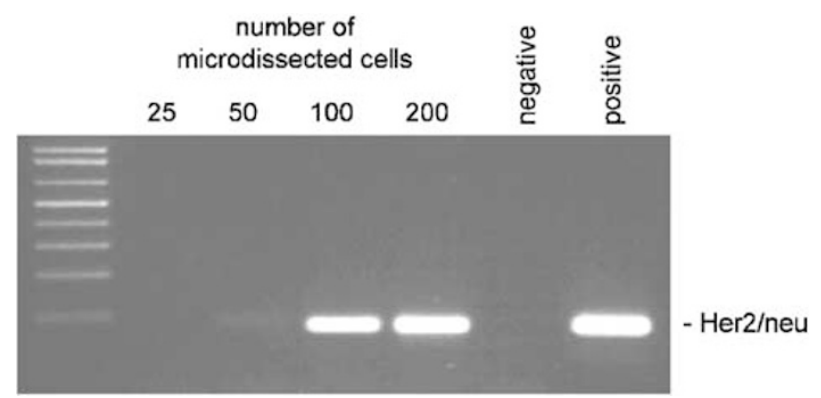

Figure 5 RNA was extracted from the indicated numbers of lasermicrodissected cells obtained from a decalcified, paraffinembedded and formalin-fixed osteosarcoma section and converted to cDNA. A measure of $1 \mu \mathrm{l}$ of each cDNA was used to amplify Her-2/neu target sequence followed by a nested PCR. PCR products were separated on a $2 \%$ agarose gel and stained with ethidium bromide. As positive control, cDNA from Saos-2 cells was used. In the negative control, RNA extraction was carried out using lysis buffer without cells.

correctly in 16 out of 17 samples analyzed (94\%). In all samples derived from tumors with good response to chemotherapy, Her-2/neu expression was lower than 1.06-fold compared to the housekeeping gene PBGD. In samples from tumors with poor response to chemotherapy six out of seven (85\%) showed Her-2/neu overexpression ranging from 1.6 to 7.9-fold. The results obtained from two different areas of the sections were comparable, demonstrating the reproducibility of the applied methods. (Figure 6 a,b).

\section{Expression of Her-2/neu Protein in Osteosarcoma Biopsies}

To investigate whether the observed Her-2/neu gene expression is associated with the expression of the Her-2/neu protein, immunohistochemical analysis of osteosarcoma biopsies was conducted using a monoclonal c-ErbB2 (Her-2/neu) antibody. In all samples analyzed, a strong cytoplasmic expression of Her-2/neu could be detected (Figure 7). However, no quantitative correlation between Her-2/neu protein- and mRNA-expression was observed.

\section{Discussion}

Histologic response to chemotherapy is currently the strongest prognostic factor in high-grade osteosarcoma, but it can only be assessed after several weeks of therapy. ${ }^{1}$ Thus, detection of chemosensitivity at the time of diagnosis would be of great clinical importance, but reliable prognostic markers are currently not available. Besides morphological and biochemical markers like tumor volume and primary tumor site ${ }^{6}$ as well as serum levels of lactate dehydrogenase and alkaline phosphatase, ${ }^{1}$ genetic markers have also been investigated. Expression of
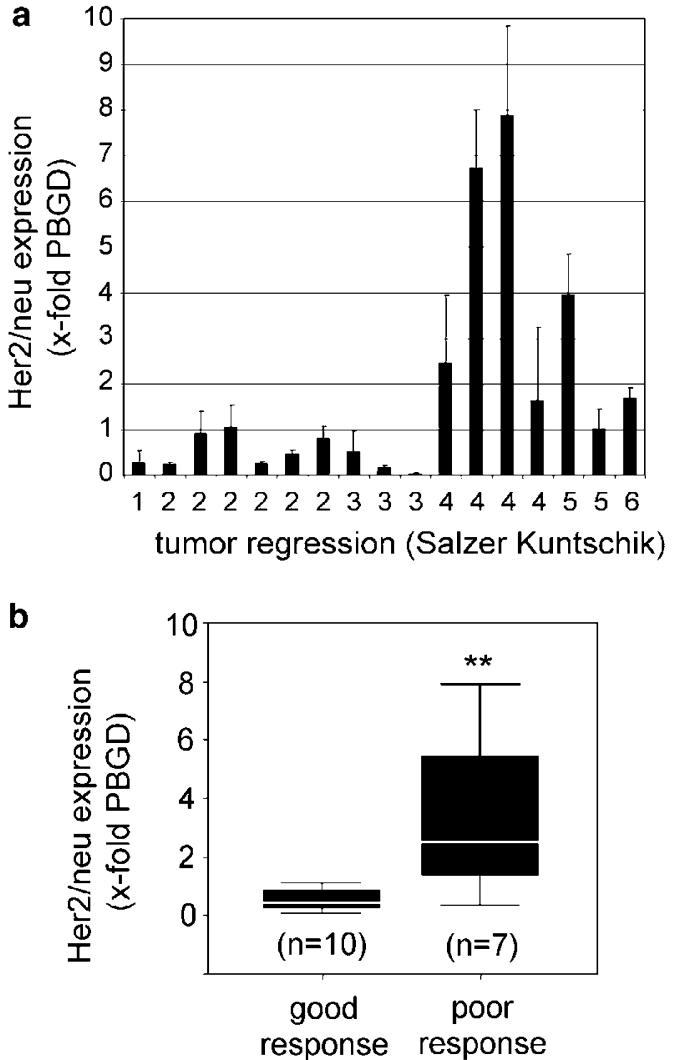

Figure 6 Analysis of Her-2/neu gene expression in laser-microdissected osteosarcoma cells derived from paraffin-embedded tissue. Transcripts were quantified by real-time quantitative RTPCR using an external standard curve. Values are expressed as $x$ fold expression compared to the housekeeping gene PBGD. (a): Her-2/neu expression was analyzed in two different areas of individual samples. Data are presented as mean \pm standard deviation. Tumor regression was assessed histologically according to the six-grade scale of Salzer-Kuntschik et al. where grade 1 denotes no viable tumor cells; grade 2, solitary viable cells or one islet of less than $0.5 \mathrm{~cm}$; grade 3 , less than $10 \%$; grade $4,10-50 \%$; grade 5 , more than $50 \%$ and grade 6 , no effect of chemotherapy. (b): Her-2/neu expression compared to therapy outcome. Good response was defined as $<10 \%$ viable tumor cells (regression grade 1-3). The white lines indicate the medians, the lower boundary of the box the 25th percentile and the upper boundary of the box the 75th percentile. The whiskers indicate the highest and lowest values. ( ${ }^{*} P=0.005$, determined by Mann-Whitney $U$ - test)

P-glycoprotein ${ }^{8}$ and Her-2/neu (erbB2) ${ }^{18}$ have been correlated with tumor regression and clinical outcome but reports are controversial. Some immunohistochemical studies demonstrated a significant correlation between Her-2/neu expression and a poor histologic response to preoperative chemotherapy, a decreased event-free survival as well as an increased risk of pulmonary metastases. ${ }^{17-19,23}$ In contrast, other studies observed Her-2/neu expression irrespective of histologic subtype and grade that was not associated with response to preoperative chemotherapy and clinical outcome. ${ }^{22}$ Further reports did not observe Her-2/neu overexpression or even reported complete absence of Her-2/neu 

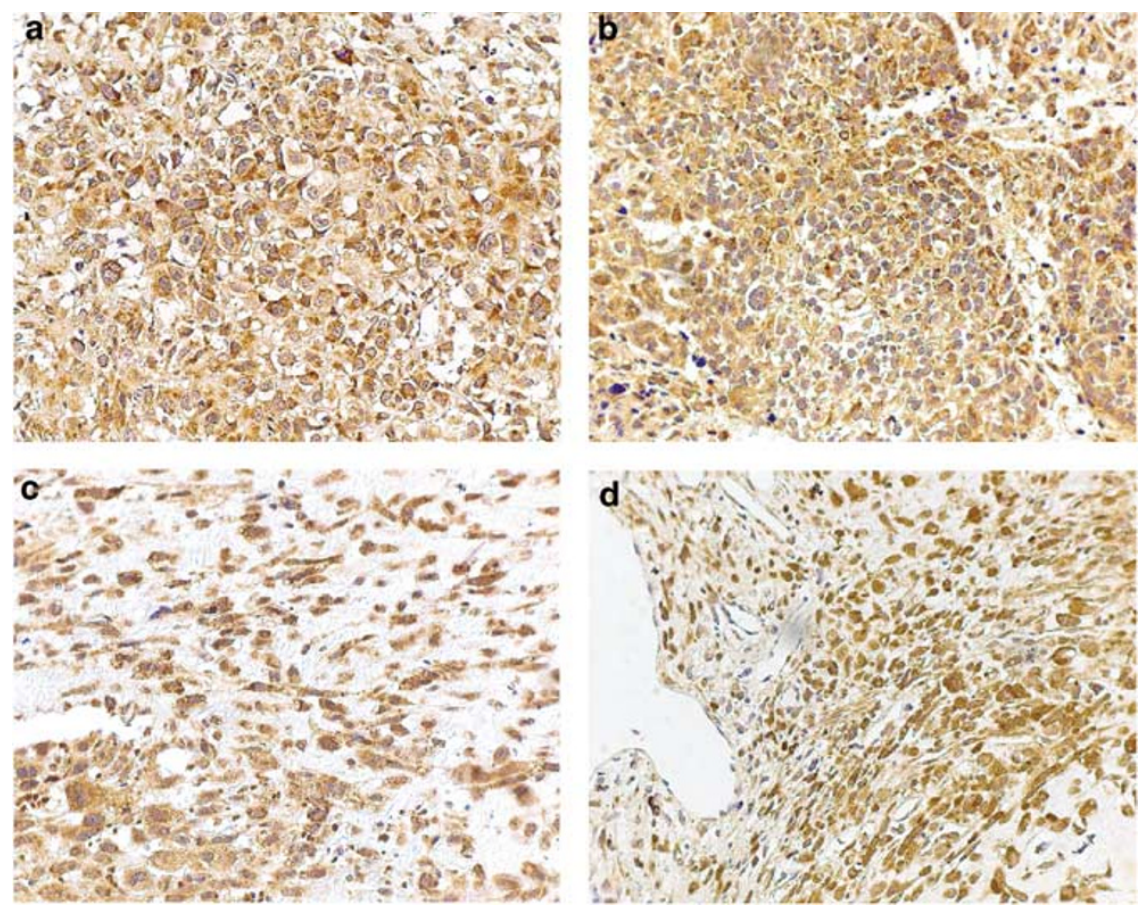

Figure 7 Immunohistochemical analysis of Her-2/neu in osteosarcoma biopsies. Representative stainings from samples with different tumor regression are shown using DAB as substrate (brown) and hematoxylin as counterstain (blue): (a) grade 2, (b) grade 3, (c) grade 4, and (d) grade 5 according to the six-grade scale of Salzer-Kuntschik.

protein and mRNA expression in osteosarcoma tissue. ${ }^{20,21}$ The reasons for these conflicting data have been extensively discussed in the literature and attributed mainly to methological and technical issues. In most studies, immunohistochemistry has been used for the detection of Her-2/neu expression on sections derived from paraffin-embedded tissue. The results are strongly influenced by various parameters including fixation, storage, antigen retrieval, type of antibody and the interpretation of the results. In most studies demonstrating Her-2/neu overexpression in osteosarcomas, only a membranous staining was considered positive, cytoplasmic staining was supposed to be negative. However, cytoplasmic staining has been shown to be of prognostic value in a variety of other carcinomas including bladder and papillary thyroid carcinoma. ${ }^{34,35}$ In addition, sensitivity and specificity of immunohistochemical Her-2/neu detection depends crucially on the antibody used..$^{24,36}$ Owing to these disadvantages of the immunohistochemical analysis of Her-2/neu protein expression, we decided to analyze mRNA expression by quantitative real-time PCR. However, the cellular heterogeneity of most tumor tissues limits the significance and interpretation of the results obtained by conventional molecular techniques in quantitative studies. The amount of contaminating bystander cells that would falsify the results is unknown in most cases. Therefore, molecular alterations like changes in gene expression cannot clearly be attributed to the cells of interest. Laser microdissection overcomes this problem by a precise removal of a morphological defined cell population from tissue sections. Selected cells are directly catapulted in a reaction tube and are then available for further molecular analyses. However, formalin fixation and in the case of osteosarcoma tissues decalcification cause an extensive degradation and chemical modification of nucleic acids leading to a significantly reduced recovery of highly fragmented RNA compared to fresh or frozen tissues. Nevertheless, it has been demonstrated that RNA from formalin-fixed paraffin-embedded tissue can successfully be used for quantitative RT-PCR analyses and that gene expression analyzed in routinely archived tissue accurately reflects the expression pattern before fixation. ${ }^{26,29,30,37}$

The goal of this study was the modification of current protocols to optimize RNA yield, efficiency of cDNA synthesis and PCR sensitivity according to the requirements of decalcified osteosarcoma tissue in order to analyze Her-2/neu gene expression. The isolation of sufficient DNA-free RNA was achieved by extensive proteinase $\mathrm{K}$ digestion of the samples in combination with a DNase treatment during RNA extraction. PCR sensitivity could be significantly increased by amplification of target cDNAs by PCR in combination with a nested quantitative real-time PCR. However, the high sensitivity causes the major problem of false-positive results due to DNA contaminations and PCR product carryover. The introduction of a second DNase treatment directly in the PCR reaction mix before the addition of template 
and primers in addition with a UV-irradiation of the work station and all instruments used completely abolished this problem and led to highly reproducible results. Thus, we could demonstrate that laser microdissection in combination with quantitative real-time PCR is a highly valuable, sensitive and reproducible tool for the cell-specific analysis of gene expression. Besides gene expression, other parameters like gene copy numbers, loss of heterozygosity, DNA methylation and mutations can be investigated in laser-microdissected samples allowing the identification of molecular profiles of specific pathological lessions. The ongoing improvement of microdissection techniques and protocols will facilitate the application of laser microdissection for cell-specific high-throughput screenings and will thus have a great impact on molecular pathology and clinical diagnosis in the future.

Using this technique, we could demonstrate for the first time Her-2/neu gene expression in lasermicrodissected osteosarcoma cells derived from tumor biopsies. In addition, a correlation between Her-2/neu expression and response to chemotherapy could be detected. Her-2/neu expression was significantly elevated in patients with poor response to chemotherapy. Defining a 1.3-fold Her2/neu expression compared to the housekeeping gene PBGD as threshold for overexpression a positive predictive value of Her-2/neu expression could be demonstrated in 16 out of 17 cases (94\%). Gene expression of Her-2/neu may thus be a useful marker for the determination of therapy outcome allowing the stratification into low-risk and highrisk patients. Risk assessment at the time of diagnosis would allow an individual adaptation of therapy improving the outcome of high-risk patients and minimizing the toxicity of therapy to low-risk patients. Besides the predictive value, Her-2/neu may also be considered as target for new therapeutic strategies in osteosarcoma treatment. Phase II studies of anti-p185 Her-2 monoclonal antibodies alone or in combination with cisplatin already provided encouraging results in the treatment of breast cancer. ${ }^{38,39}$ The demonstrated advantages of gene expression analyses over immunohistochemical studies and the possibility to analyze archival material facilitates the validation of our results by larger retrospective investigations.

\section{References}

1 Meyers PA, Heller G, Healey J, et al. Chemotherapy for nonmetastatic osteogenic sarcoma: the Memorial Sloan-Kettering experience. J Clin Oncol 1992;10:5-15.

2 Provisor AJ, Ettinger LJ, Nachman JB, et al. Treatment of nonmetastatic osteosarcoma of the extremity with preoperative and postoperative chemotherapy: a report from the Children's Cancer Group. J Clin Oncol 1997;15:76-84.
3 Meyers PA, Heller G, Healey JH, et al. Osteogenic sarcoma with clinically detectable metastasis at initial presentation. J Clin Oncol 1993;11:449-453.

4 Rosen G, Caparros B, Huvos AG, et al. Preoperative chemotherapy for osteogenic sarcoma: selection of postoperative adjuvant chemotherapy based on the response of the primary tumor to preoperative chemotherapy. Cancer 1982;49:1221-1230.

5 Winkler K, Bielack SS, Delling G, et al. Treatment of osteosarcoma: experience of the Cooperative Osteosarcoma Study Group (COSS). Cancer Treat Res 1993;62:269-277.

6 Bieling P, Rehan N, Winkler P, et al. Tumor size and prognosis in aggressively treated osteosarcoma. J Clin Oncol 1996;14:848-858.

7 Meyers PA, Gorlick R. Osteosarcoma. Pediatr Clin North Am 1997;44:973-989.

8 Baldini N, Scotlandi K, Serra M, et al. P-glycoprotein expression in osteosarcoma: a basis for risk-adapted adjuvant chemotherapy. J Orthop Res 1999;17: 629-632.

9 Bargmann CI, Weinberg RA. Increased tyrosine kinase activity associated with the protein encoded by the activated neu oncogene. Proc Natl Acad Sci USA 1988;85:5394-5398.

10 Ross JS, Fletcher JA. HER-2/neu (c-erb-B2) gene and protein in breast cancer. Am J Clin Pathol 1999;112:S53-S67.

11 Bongiorno PF, Whyte RI, Lesser EJ, et al. Alterations of K-ras, p53, and erbB-2/neu in human lung adenocarcinomas. J Thorac Cardiovasc Surg 1994;107:590-595.

12 Cirisano FD, Karlan BY. The role of the Her-2/neu oncogene in gynecologic cancers. J Soc Gynecol Invest 1996;3:99-105.

13 Slamon DJ, Clark GM, Wong SG, et al. Human breast cancer: correlation of relapse and survival with amplification of the Her-2/neu oncogene. Science 1987;235:177-182.

14 Cobleigh MA, Vogel CL, Tripathy D, et al. Multinational study of the efficacy and safety of humanized anti- HER 2 monoclonal antibody in women who have HER2-overexpressing metastatic breast cancer that has progressed after chemotherapy for metastatic disease. J Clin Oncol 1999;17:2639-2648.

15 Pegram MD, Konecny G, Slamon DJ. The molecular and cellular biology of HER2/neu gene amplification/ overexpression and the clinical development of herceptin (trastuzumab) therapy for breast cancer. Cancer Treat Res 2000;103:57-75.

16 Esteva FJ, Valero V, Booser D, et al. Phase II study of weekly docetaxel and trastuzumab for patients with HER2-overexpressing metastatic breast cancer. J Clin Oncol 2002;20:1800-1808.

17 Gorlick R, Huvos AG, Heller G, et al. Expression of HER2/erbB-2 correlates with survival in osteosarcoma. J Clin Oncol 1999;17:2781-2788.

18 Onda M, Matsuda S, Higaki S, et al. ErbB-2 expression is correlated with poor prognosis for patients with osteosarcoma. Cancer 1996;77:71-78.

19 Morris CD, Gorlick R, Huvos G, et al. Human epidermal growth factor receptor 2 as a prognostic indicator in osteogenic sarcoma. Clin Orthop 2001; 382:59-65.

20 Thomas DG, Giordano TJ, Sanders D, et al. Absence of HER2/neu gene expression in osteosarcoma and skeletal Ewing's sarcoma. Clin Cancer Res 2002;8:788-793. 
21 Maitra A, Wanzer D, Weinberg AG, et al. Amplification of the HER2/neu oncogene is uncommon in pediatric osteosarcomas. Cancer 2001;92:677-683.

22 Kilpatrick SE, Geisinger KR, King TS, et al. Clinicopathologic analysis of HER-2/neu immunoexpression among various histologic subtypes and grades of osteosarcoma. Mod Pathol 2001;14:1277-1283.

23 Zhou H, Randall RL, Brothman AR, et al. Her-2/neu expression in osteosarcoma increases risk of lung metastasis and can be associated with gene amplification. J Pediatr Hematol Oncol 2003;25:27-32.

24 Press MF, Hung G, Godolphin W, et al. Sensitivity of HER2/neu antibodies in archival tissue samples: potential source of error in immunohistochemical studies of oncogene expression. Cancer Res 1994;54:2771-2777.

25 Walch A, Specht K, Smida J, et al. Tissue microdissection techniques in quantitative genome and gene expression analyses. Histochem Cell Biol 2001; 115:269-276.

26 Lehmann U, Bock O, Glockner S, et al. Quantitative molecular analysis of laser-microdissected paraffin-embedded human tissues. Pathobiology 2000;68:202-208.

27 Fend F, Specht K, Kremer M, et al. Laser capture microdissection in pathology. Methods Enzymol 2002;356:196-206.

28 Goldsworthy SM, Stockton PS, Trempus CS, et al. Effects of fixation on RNA extraction and amplification from laser capture microdissected tissue. Mol Carcinogen 1999;25:86-91.

29 Lehmann U, Kreipe H. Real-time PCR analysis of DNA and RNA extracted from formalin-fixed and paraffinembedded biopsies. Methods 2001;25:409-418.

30 Godfrey TE, Kim SH, Chavira M, et al. Quantitative mRNA expression analysis from formalin-fixed, paraffin-embedded tissues using $5^{\prime}$ nuclease quantitative reverse transcription-polymerase chain reaction. J Mol Diagn 2000;2:84-91.

31 Specht K, Richter T, Muller U, et al. Quantitative gene expression analysis in microdissected archival formalin-fixed and paraffin-embedded tumor tissue. Am J Pathol 2001;158:419-429.
32 Masuda N, Ohnishi T, Kawamoto S, et al. Analysis of chemical modification of RNA from formalin-fixed samples and optimization of molecular biology applications for such samples. Nucleic Acids Res 1999;27:4436-4443.

33 Salzer-Kuntschik M, Brand G, Delling G. Determination of the degree of morphological regression following chemotherapy in malignant bone tumors]. Pathologe 1983;4:135-141.

34 Coombs LM, Pigott DA, Sweeney E, et al. Amplification and over-expression of c-erbB-2 in transitional cell carcinoma of the urinary bladder. $\mathrm{Br} \mathrm{J}$ Cancer 1991;63:601-608.

35 Akslen LA, Varhaug JE. Oncoproteins and tumor progression in papillary thyroid carcinoma: presence of epidermal growth factor receptor, c-erbB-2 protein, estrogen receptor related protein, p21-ras protein, and proliferation indicators in relation to tumor recurrences and patient survival. Cancer 1995;76 1643-1654.

36 Gancberg D, Lespagnard L, Rouas G, et al. Sensitivity of HER-2/neu antibodies in archival tissue samples of invasive breast carcinomas. Correlation with oncogene amplification in 160 cases. Am J Clin Pathol 2000; 113:675-682.

37 Imamichi Y, Lahr G, Wedlich D. Laser-mediated microdissection of paraffin sections from Xenopus embryos allows detection of tissuespecific expressed mRNAs. Dev Genes Evol 2001; 211:361-366.

38 Pegram MD, Lipton A, Hayes DF, et al. Phase II study of receptor-enhanced chemosensitivity using recombinant humanized anti-p185 HER2/neu monoclonal antibody plus cisplatin in patients with HER2/neuoverexpressing metastatic breast cancer refractory to chemotherapy treatment. J Clin Oncol 1998;16: 2659-2671.

39 Baselga J, Tripathy D, Mendelsohn J, et al. Phase II study of weekly intravenous recombinant humanized anti-p185 HER2 monoclonal antibody in patients with HER2/neu-overexpressing metastatic breast cancer. J Clin Oncol 1996;14:737-744 